in some places, and sticking to the clay cylinder. This, I think, is sufficient evidence that the clay, or some impurity contained in it, attacks the wire, otherwise the local nature of the action could not be explained, unless the quality of the wire used was very inferior.

"I have tried several materials on which to wind the wire, but have found nothing that answers so well as mica. The plan I generally adopt is to double the wire on itself, and wind it round a very thin plate of mica, in such a way that it only touches the mica at the edges. This method gives very good insulation, even at high temperatures, and, so far as I can discover, the mica has no action on the wire even at temperatures of $1200^{3} \mathrm{C}$.

"Another defect of the Siemens pyrometer is the iron-containing tube. Metallic vapours of any kind will attack the wire readily, and will ruin the pyrometer. It is not probable that the iron itself will be appreciably volatile at temperatures below $1000^{\circ} \mathrm{C}$., but it is very likely to contain several more volatile impurities. Vapours of copper, tin, zinc, \&c., rapidly render the wire britle and useless. A comparatively small trace suffices."

Mr. Callendaı's wires were inclosed in glass, a material which naturally cannot be used for high temperatures. He finds that a hard-glazed porcelain tube does very well to protect the wire, at least up to temperatures of $1200^{\circ} \mathrm{C}$. A silica tube would be better, but that the author has not succeeded in obtaining. $\mathrm{He}$ pointed out, however, that good porcelain is not so fragile as it is generally thought to be. He has only broken one tube, and that with a hammer. He hopes, however, ultimately to be able to produce a satisfactory silica tube. The remainder of the paper was taken up with a description of the indicating apparatus, but here, again, we must refer our readers to the original paper.

Mr. Thwaites's paper is of far too formidable proportions for us to deal with in anything like detail in this notice. $\mathrm{He}$ describes calorimeters, pyrometers, \&c., and their uses. A good deal of the matter put forward is not altogether new.

Mr. Wingham's paper on the slide rule is of value to those interested in the practical working of blast furnaces.

Mr. Wailes's gas furnace valve has been designed to give an absolutely air-tight closing, an effect which is obtained by a water seal. Illustrations were given by means of wall diagrams.

The meeting was brought to a cluse with the usual votes of thanks.

The autum' meeting will be held in Liverpool, but the date is not yet fixed.

\section{THE YEARLY ADMISSIONS TO THE ROYAL SUCIETY.}

THE discussions that arose in connection $\mathrm{w}$ ith the revision of the Statutes of the Royal Society during the years 1890 and 1891 , led me to endeavour to obtain definite data on which to found a trustworthy opinion as to the effect of the existing limitation of the number of yearly admissions on the eventual total strength of the Society, and the probable result of increasing the number beyond fifteen, the present limit.

The facts bearing on this subject, so far as I have been able to collect them from the records of the Society, are embodied in the tables annexed to this communication, for the proper appreciation of the significance of the figures in which a few preliminary explanations are necessary.

The anniversary of the Society being fixed for November 30 in each year, the customary record of the number of Fellows for any year refers to the number on that date. I have throughout regarded the date to which this number applies as being January $\mathbf{I}$ of the following year.

The annual election of Urdinary Fellows usually takes place in the first or second week of June in each year. I have considered the date to be January I of the same year.

The lapses, whether from death or other causes, have been treated as having occurred at the end of the calendar year in which they take place.

These assumptions have been made to simplify the various

I "On the Probable Effect of the Limitation of the Nunber of Ordinary Fellows elected into the Royal Society to Fifteen in each Year on the eventual Tutal Number of Fellows." By Lieut.-General R. Strachey, R.E., accompan.ed by four tables, presenting summaries of the author's results. computations that the investigation required (which have been sufficiently troublesome as it is), and owing to the considerable period dealt with, forty-three years, the results will not, I believe, be sensibly affected thereby.

Unless it is otherwise specifically stated, the numbers refer exclusively to the Ordinary' Fellows, elected at the regular annual meetings fixed for the purpose.

So far as I have been able to ascertain (for the earlier records in many particulars are defective), the number of Ordinary Fellows elected since 1848 has been 15 in each year, except on four occasions; in two years the number having been 14 , and in two years 16 : the average, therefore, is 15 yearly.

During the period since 1848 , the number of Royal and Honorary Fellows has been about 5 , and the Foreign Members about 50; these are included in the total number of Fellows shown in the annual reports of the Council, but will not be further considered in what follows.

The rules under which certain privileged classes have been admitted as Fellows, in addition to the Ordinary Fellows, have varied somewhat since 1848 , but at present, apart from the persons eligible for the classes of Fellows above excluded, the only persons so privileged are Privy Councillors. The total number of Privileged Fellows elected since 1848 seems to have been 75, which for 43 years gives an average of 175 per annum.

Table I. contains a summary of the available data relating to the total number of Fellows since 1848 .

The total number, excluding Royal, Honorary, and Foreign Fellows, at the commencement of 1848 was 768 . I am not able to say how many of these were Fellows elected in the ordinary way, and how many were privileged, but this has no importance for my present object. From I860 onwards the distinction between the three classes, those elected before I848, Privileged Fellows, and Ordinary Fellows, is exhibited.

At the end of 1890 , the total number of Fellows, excluding the Royal, Honorary, and Foreign Classes, was 463 ; of whom 26 were Fellows elected before 1848,36 were Privileged Fellows elected since $184^{8}$; and 401 Ordinary Fellows elected since I 848 .

Hence it appears that the reduction of number of Fellows, of the three classes last referred to, has been 305 , and as the number of admissions of the Privileged class has not been very materially affected by the changes in the rules relating to them, it follows that virtually the whole of this large reduction is a consequence of the restriction, to $\mathrm{I}_{5}$, of the number of Ordinary Fellows elected yearly.

As the ages of the 768 Fellows who constituted the bulk of the Society in 1848 are not known, and as the conditions of election before that year differed materially from what they have been since, no very useful conclusions can be drawn from the rate of their diminution since 1848 .

Assuming, however, that the number of Privileged Fellows in 1848 was, as is probable, about 50 , there would remain 718 Ordinary Fellows, of whom in 43 years 692 lapsed, or at an average yearly rate of 2.24 per cent., that is rather more than I6 a year. This rate, as I shall show subsequently, does not differ greatly from that which has prevailed among the Ordinary Fellows elected since 1848 , and it may therefore be presumed that the averaye age of the Fellows in that year did not differ greatly from the average age since.

Table II. gives, as far as available data admit, the ages at the time of election of all Fellows elected since 1848 ; and shows the number of years they severally survived, the average age at election, the number and average age of those who were ative in 1891 , and the greatest and least ages of Fellows elected in each year.

From this table it will be seen that there has been a gradual small increase in the age at election; the average for the first Io years having been $42^{\circ} 2$; for the second Io years, $43^{\circ} \mathrm{O}$; for the third 10 years, 44.8 ; and for the last 13 years, $45^{\circ} 2$.

The accuracy of these conclusions may be somewhat affected by the greater number of unknown ages in the earlier years, the age when unknown having been taken at the average of the group of years in which the election took place.

The least age at which any Fellow has been elected is 24, one such case being recorded. The average minimum at any election is slightly under 30 , and the average maximum is rather over 63; one election at an age of 87 is recorded, and several above 70 .

The oldest survivor of the Fellows elected since 1848 , who alone are dealt with in this table, was 86 years of age in 1891 .

$$
\text { No. } 1179 \text {, voL. 46] }
$$


The average age at election was $43^{\circ} 9$, and the average age of all the Fellows in $189 \mathrm{I}$ was 58.4.

Table III. records the numhers of Ordinary ${ }^{\circ}$ Fellows elected in each year, and remaining alive in each year after election, until $\mathrm{x} 8 \mathrm{~g} \mathrm{r}$.

From this it will be seen that during the last ten years the numbers have increased by 46 ; in the previous ten years the increase was 68 , or 22 more ; and in the ten years still earlier the increase was II I, or 43 more than the last. If the decrease of growth for the ten years after 1890 takes place in a similar ratio to that which took place between $1870-80$ and $1880-90$, we might anticipate an increase of only iI up to 1900, or probably a smaller number.

In order to obtain a satisfactory comparison between the lives of the Fellows, and those of the general population as shown in the accepted life tables, I have calculated, from the known ages of the Fellows at election, and the known dates of the deaths that have occurred among them, the average age of the Fellows remaining alive in each year. From these ages I have computed, from Dr. Farr's tables, the probable number of Fellows that would survive from year to year, assuming the initial number to be 15 .

From Table III., above referred to, has been ascertained the number of Fellows surviving in each successive year after election, and thence has been obtained the average number surviving from an initial number 15 .

The results of these computations will be found in Table IV.

The second column in this table shows the number of lives dealt with for each year after election. The first entry, 645, is the total number of Fellows elected in the whole 43 years. The next column to the right gives their aggregate ages, and the next their average age, $44^{\circ}$, in their first year. Following the same line to the right, we find the average number of Fellows elected, and in their first year.

Passing to the second line of the table, 619, immediately below 645 , is the total number of Fellows remaining in their second year from the elections of 42 years; this is succeeded, in the columns to the right, by their aggregate ages in their second year and their average age, and the average number in their second year, out of 15 , the average number elected.

The third line gives the same data for the third year of Fellowship, and so on throughout, the last line but one showing that in their 42nd year there remained 6 Fellows from the elections of 2 years, with an aggregate age of 444 years, and an average age of $74^{\circ} \mathrm{O}$, the average number surviving in their 42 nd year, out of the 15 elected, being 3 .

The sixth column of the table gives the successive sums of the numbers in the fifth column, and therefore indicates the aggregate number of Fellows that will, on the average, be surviving in each successive year of Fellowship, the number elected in each year being always supposed to be 15 .

It will be seen that the total for the $43^{\text {rd }}$ year is $397^{\circ} \mathrm{o}$, whereas the actual number surviving, shown in column XI., is 40I. This difference is of course due to the number 397 representing what the result would be if the average rates of election and decrease prevailed, instead of the actual rates for the separate years; and it is probably sufficiently accounted for by the fact, already pointed out, of the gradually increasing age at election in the later years, which will lead to the lives in the earlier years of the series bein' somewhat better than the average. Column XI. shows the actual results for successive vears corresponding to the average results given in column VI. The differences will be seen to be somewhat irregular, but nowhere to be of importance.

Column VII. gives the aggregate ages of the numbers surviving in successive years, as shown in column V., and from it is deduced the average age of the whole number of Fellows shown in column VI., 397, which is seen to be 57.7 years, a result differing slightly from that obtained from the actual ages of the Fellows surviving in $189 \mathrm{r}$, which was shown to be $58^{\circ} 4$. The cause of this difference has already been indicated.

Columns VIII, and IX. supply the results that would be obtained by applying to an initial number of 15 , the rates of mortality in Dr. Farr's tables, for the ages in successive years given in column IV. Column $\mathrm{X}$. contains the ratio of column VI. to column IX., and indicates that throughout the whole period of 43 years the actual results are somewhat better than the tabular results, or that the lives of the Fellows are better than the ordinary lives, and that this advantage leads in the $43^{\text {rd }}$ year to the actual number of survivors being rather more than 5 per cent. in excess of that which would be given hy the life tables, or of about 20 on a total of 400 .

An examination of this table will show that, with the excep tion of the last six or eight years, in which the number of lives dealt with at last becomes very small, the figures indicate a very regular and consistent progression, and it will practically be quite safe to assume that the series in column VI. may be extended on the basis of the ordinary life tables, subject to the addition of 5 per cent. on the total amounts obtained from these last.

IIence it will be found that in 10 years after 189 i the aggregate number of Fellows is not at all likely to he increased hy more than 15 , that the final result 11 ay be as little as 4 ro, hut is not likely to be more than 420 , or at the outside 425 .

In an earlier part of this paper, I mentioned that the rate of decrease of the Ordinary Fellows elected before 1848 did not appear to differ materially from that which has prevailed subsequently.

Taking the number of Ordinary Fellows elected before 1848 , and then alive, at 718 , it will be found that in 12 Jears ( 1860 ) the number was reduced to 422 , which is about 60 per cent. of the original number; after 24 years $(\mathbf{I} 872)$ the number fell to 206 , which is about 30 per cent. of the original; and in 36 years (1884) there remained only 65 , which is about 9 per cent. of the first number.

Assuming that the average age of the 718 Fellows elected before 1848 , and then alive, wa: not materially different from (58) the average age of the Fellows elected after 1848 and alive in 1891 , when it has probably become nearly stationary, it may be inferred that the lapses among a body of Fellows of that age will correspond to the lapses among the Fellows alive in 1848 . Now, from Table IV it will be seen that of the Fellows elected after 1848 , the average age in their 17 th year was 58.3 years, which is almost exactly the average age of the whole body. Further, it is shown that of the supposed original 15 there remained $10^{\circ} 9$ in the 17 th year of the age above mentioned, $58 \cdot 3$. This number was reduced in 12 years to $6 \%$, which is nearly 60 per cent. of the number in the $\mathbf{I} 7$ th year, and again falls after $\mathbf{I} 2$ years more to $3^{\cdot} 7$, which is not very different from $3^{\circ}$ per cent. of the starting number, and after I 2 years more the number will be seen to be likely to be less than $\mathrm{I}^{\circ} \mathrm{O}$, which again will not differ materially from 9 per cent. of the original Io' 9 . These proportions, it will have been observed, are those above shown to hold in the case of the Fellows elected before $\mathrm{I} 848$.

On the whole, it seems to be established that the present restriction to 15 of the number of Ordinary Fellows elected in any year will lead to an eventual maximum number not exceeding 420 ; and that the ultimate increase of the total strength of the Society, for each additional Fellow elected in excess of 15 may be taken at 28 , so that an increase to 18 of the annual number of Ordinary Fellows elected would lead to an ultimate total of 500 such Fellows.

\section{THE ERUPTIONS OF VULCANO} (AUGUST 3, 1888, TO MARCH 22, 1890). ${ }^{1}$

THERE are some 180 (nominally $2 \mathrm{I} 2$ ) pages and II plates. Of these latter 4 are reproductions of Silvestri's beautiful whole-plate photographs [one of Vulcano at rest (with Vulcanello), and the other three instantaneous views of the volcano in eruption]. A fifth reproduces, half-size, two of Dr. JohnstonLavis's instantaneous views of eruptions taken from the crater's edge. ${ }^{2}$ Two other plates give I4 excellent photographs of the "bombs," and of the rest two are sketches of Stromboli crater, one petrographical, and the last the map of Vulcano $(\mathrm{I} / 50,000)$

I "Le Eruzione dell' Isola di Vulcano, incominciate il 3 agosto, 1888 , e terminate il $22 \mathrm{M}$ arzo, 1890 : Relazione scientifica della Commissione incaricata degli studi dal R. Governo," Annali dell' Ufficio Centrale di Meteorologicae Geodinamica, Parte 4, vol. x., $x 888$ (Rome, $189 \mathrm{r}$ ).

The Commission was originally as follows :- President, Prof. O. Silvestri (Catania), Prof, G. Mercalli (Milaz), Prof. Grablovitz (Seismological Observatory, Ischia), and as engineer, V. Clerici (Messina), with A. Cerati, Prof. Ponte, and A. Silvestri, as assistants.

As is known, Prof. Silvestri died before the publication of the Report, but not till some months after the end of the eruptions, on which he had elsewhere published various papers. The Commission must thus have had full time to profit by his excerience both in the field and afterwards, and his name appears as anthor or joint author of a number of sections. After Silvestri's death. Prof. Mercalli, the largest contributor to this Report, took his place, and brought the work to its completion.

2 For others by Dr. Lavis and Silvestri, see "South Italian Volcanoes."

No. II 79 , vol. 467 